Original Contribution

\title{
EXPLORATION OF THE IMPACT OF THE EXTRACTION PARAMETERS ON BIOLOGICAL ACTIVE SUBSTANCES IN THE EXTRACTS FROM DRIED FRUIT BLACK BLUEBERRY (VACCINIUM MYRTILLUS L.)
}

\author{
A. Georgieva*, R. Stefanova, Kr. Krastev
}

Faculty of Technics and Technologies, Trakia University, Yambol, Bulgaria,

\begin{abstract}
The optimal parameters of the extraction process for the extraction of biologically active substances from the dried fruits of black blueberry have been established and experimentally confirmed. The phenolic complex of the extracts obtained at different parameters of the extraction process was investigated - selection of the extractant; extraction temperature; extraction time and hydromodule. Studied are the extracts obtained at the optimals extraction parameters for total phenols 7,34 g gallic acid / $100 \mathrm{~g}$ dry substance, phenolcarboxylic acids $0,61 \%$, flavonoid phenolic compounds $194 \mathrm{mg} \%$, sum anthocyanins $115 \mathrm{mg} \%$ and tannins 8,76 g catechin / 100g dry substance. On the basis of the experimental data, the technological regimes of the extraction process were selected. The use of $70 \% \mathrm{C}_{2} \mathrm{H}_{5} \mathrm{OH}$ as an extractant is technologically warranted to produce extracts of dried fruits black blueberry with maximum content of phenols, flavonoids, anthocyanins and tannins. Technologically justified extraction temperature is $65-80^{\circ} \mathrm{C}$. By increasing the extraction temperature to $80^{\circ} \mathrm{C}$, the quantity of anthocyanins in the extracts increases, which positively affects the organoleptic evaluation of the final products. The optimum extraction time is 3-4 hours. During this extraction period, a maximum content of the phenolic complex is obtained. The results obtained suggest that the most advantageous hydromodul for extraction is $1: 30$.
\end{abstract}

Keywords: extraction parameters, extracts, biologically active substances, dried fruit black blueberry.

\section{INTRODUCTION}

Studies conducted in different countries confirm that one of the main causes of pathological changes in the human body leading to premature aging and development of cardiovascular diseases, oncological diseases and diabetes is the excessive accumulation of free radicals and active forms of oxygen in the biological fluid of the organism. In order to increase the nutritional value and antioxidant properties of the juice-containing beverages, extracts of wild raw materials having prophylactic and functional action can be introduced into production technologies. The healing potential of wild shrub plants lies in their antioxidant, anti-allergic, antiinflammatory and antiviral properties, which

\footnotetext{
*Correspondence to: Antoaneta Georgieva, PhD, Associate professor, Trakia University, faculty of Technics and technologies, Yambol, Bulgaria, email:ageorgieva@ftt.uni-sz.bg
}

depend on polyphenolic complexes. Particular attention is given to the content of flavonoid phenolic compounds and anthocyanin pigments.

Black blueberries extracts serve as natural antioxidants. Berries contain powerful antioxidants and a proper balance of bioactive compounds.

Wild plants and fruits are multicomponent systems with complex interactions that can be embedded in the physiological antioxidant system of cells in the body, be drawn to it, and form new relationships and interactions between all components of the system $(1,2)$.

As an alternative to the synthetic antioxidants, natural polyphenols from various plant species may be used. These compounds have an ideal chemical structure to "scavenge" free radicals, demonstrating, at the same time, higher 
antioxidant capacity (e.g., cyanidin and malvidin) than vitamins $\mathrm{C}$ and $\mathrm{E}(3)$.

Owing to these properties, polyphenols protect and support many functions of organs and systems and in particular the digestive systems (4).

Anthocyanins are representative plant pigments widely distributed in colored fruits and flowers. They also exhibit antioxidant activities and therefore may contribute to the prevention of heart disease, cancer, and inflammatory disease (5-9). Berries have been known to contain anthocyanin pigments abundantly and thus have been used globally as a medicine or a source of health food/dietary supplement.

The purpose of this work is to determine, through research, the technologically sound parameters of the extraction process and to obtain extracts with a maximum BAV content.

The following tasks have been set to achieve this goal:

- establishment of the basic parameters of the process of extraction and development of technology for the extraction of BAV from the dried fruits of blackblueberry with the highest content of the phenolic complex.

- study of total phenolic compounds, phenolcarboxylic acids, flavonoid phenolic compounds, the sum of anthocyanins and tannins from the extracts obtained at different parameters of the extraction process.

\section{MATERIAL AND METHODS}

Object of study are the dry fruits of black blueberry. In fruits contain a number of BAV that can affect the vital processes occurring in the human body.

The physicochemical analyzes were conducted using standardized methods approved by good manufacturing practice.

- General Phenol Compounds (AFS) spectrophotometric method with Folin-Denisa reagent, $\%$ as gallic acid (10).

- Phenol Carbonic Acid Spectrophotometric by Pharmacopoeia Method [Pharmacopoeia Russia]. General method of analysis (10).

- Flavonoid phenolic compounds spectrophotometric as a rutin, $\%$ by pharmacopoeial method [Pharmacopeia Russia]. General method of analysis (10).
GEORGIEVA A., et al.

- Anthocyanins - spectrophotometric such as cyanidine-3,5-diglucoside, by pharmacopoeial method [Pharmacopoeia Russia]. General method of analysis (10).

- Tanning substances - titrated with $0.02 \mathrm{M}$ potassium permanganate, $\%$ by pharmacopoeial method [Pharmacopoeia Russia]. General method of analysis (10).

For the extraction of the vegetable raw material, various extractants are used: water and ethyl alcohol of various concentrations $30 \%, 50 \%$ and $70 \%$. Concentration of the ethanol has a significant effect on the extraction of the various groups of compounds. To determine the optimum solvent, extractant is added to a raw material. The feedstock / extractant ratio was $1: 10$ by weight of feedstock at $20^{\circ} \mathrm{C}$ for 24 hours. The change in concentration of the different groups of compounds in the extracts is due to their different solubility in ethanol and water and to the fact that they are extracted from dry plant material. Processes in plant raw materials are going on into the aquatic environment. Most of the compounds are found mainly in the vacuoles of the cells. To improve the extractability of the substances contained in dry plant tissue, the raw material needs to absorb a certain amount of water. Water-alcohol solutions at a concentration close to absolute ethanol do not provide the necessary water to rehydrate the cells.

The effect of the hydromodule (1:10, 1:20 and $1: 30)$, the temperature $(35 \mathrm{oC}-80 \mathrm{oC})$ and the duration of the extraction (1-4 hours) on the type and quantity of the extracted substances were investigated. Developed various variants of water and ethanol extracts from dried berries black blueberry have been. The aqueous and ethanol extracts of the fruits are respectively at hydromodul 1:10, 1:20 and 1:30 - fruit / extractant; at an extraction temperature of $35^{\circ}, 50^{\circ}, 65^{\circ}$ and $80^{\circ} \mathrm{C}$ and extraction time $1,2,3$ and 4 hours. The extracts are stored in tightly closed packages at $25^{\circ} \mathrm{C}$ in the dark. Each variant is developed in triple repeatability. The resulting extracts were subjected to physico-chemical analyzes. As a result of the research the process of extraction of phenolic compounds from dried fruit black blueberry was optimized.

\section{RESULTS}

For the extraction of the vegetable raw material, various extractants are used: water and ethyl alcohol of various concentrations $30 \%, 50 \%$ and $70 \%$ (Figure 1). 


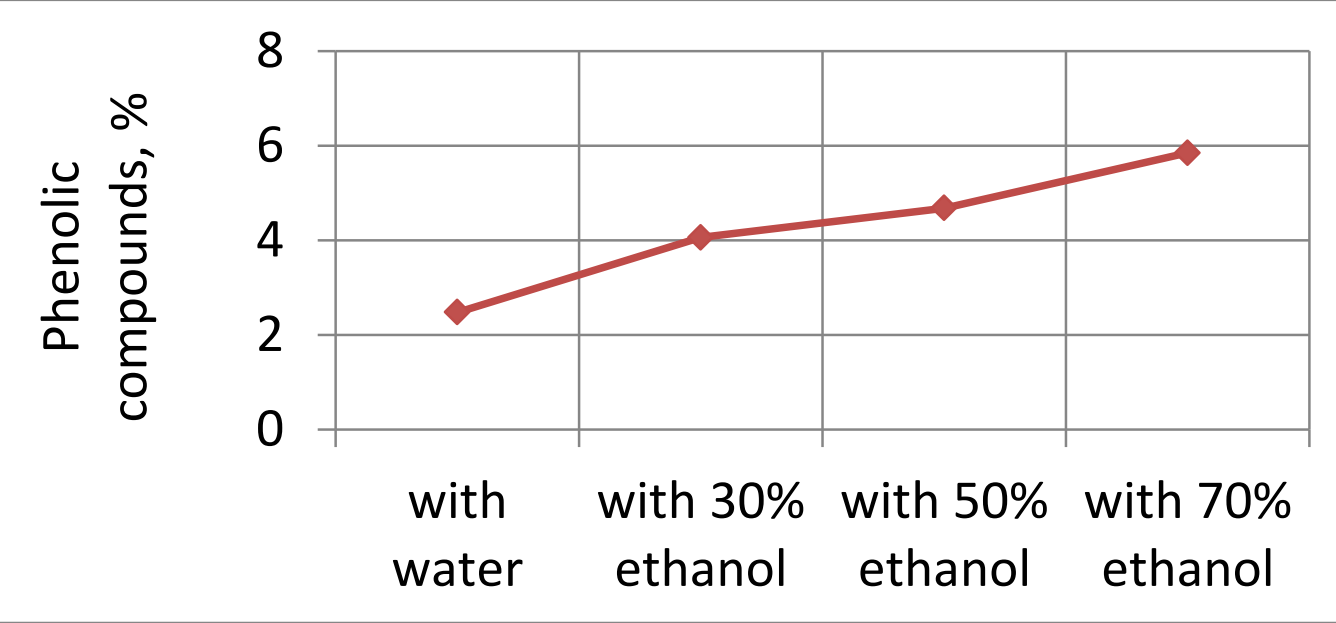

Figure 1. Effect of the extractant concentration on the the total phenolic compounds content in extracts of dried fruits black blueberry

The trend in the content of phenolcarboxylic acids and flavonoid phenolic compounds is similar to that for the general phenolic compounds (Figure 2 and Figure 3).

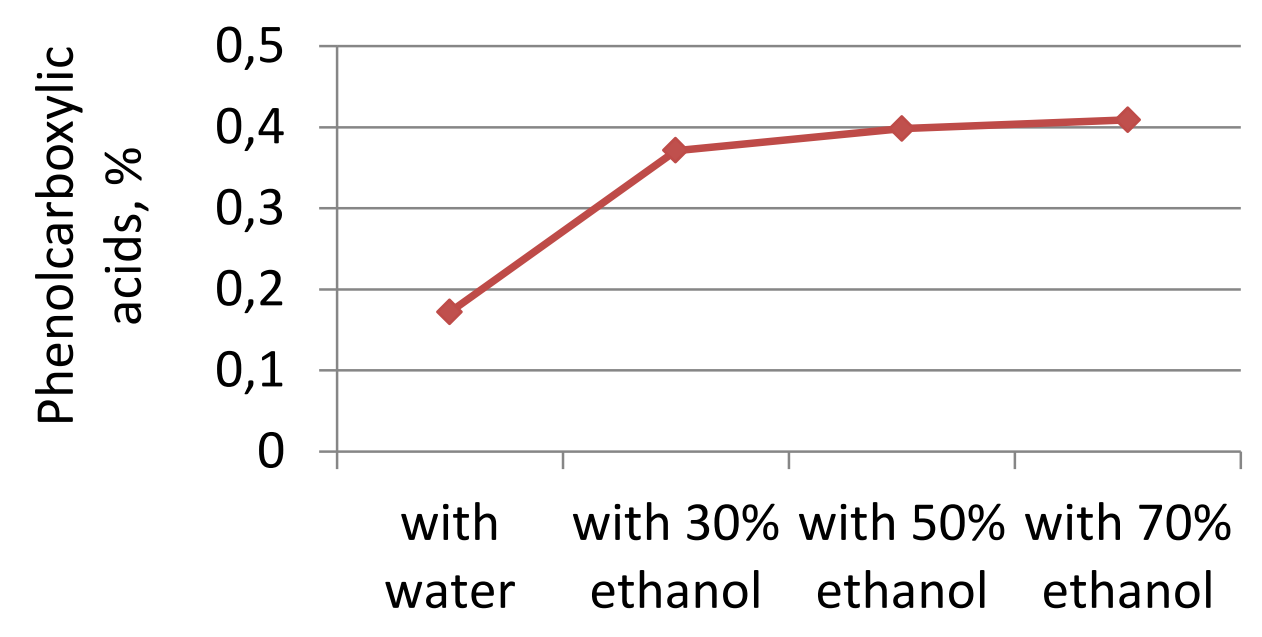

Figure 2. Effect of extractant concentration on phenolcarboxylic acids content in extracts of dried fruits black blueberry

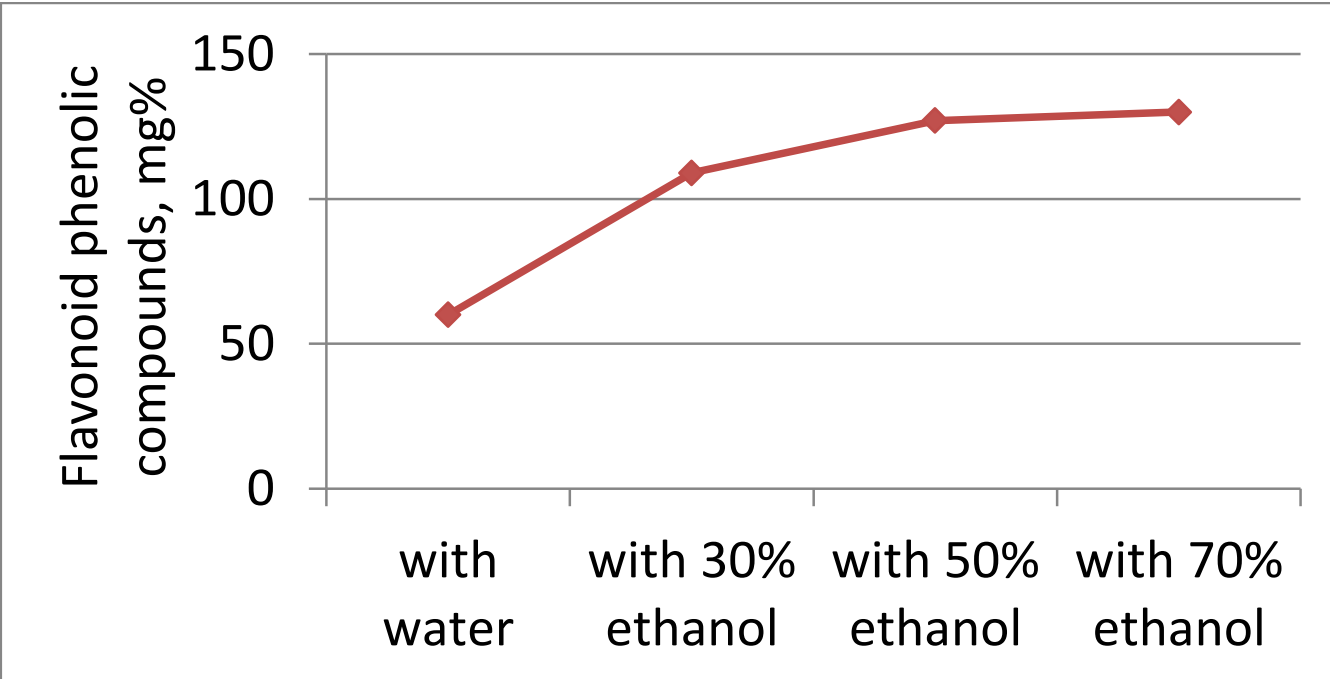

Figure 3. Effect of extractant concentration on flavonoid phenolic compounds content in extracts of dried fruits black blueberry 
GEORGIEVA A., et al.

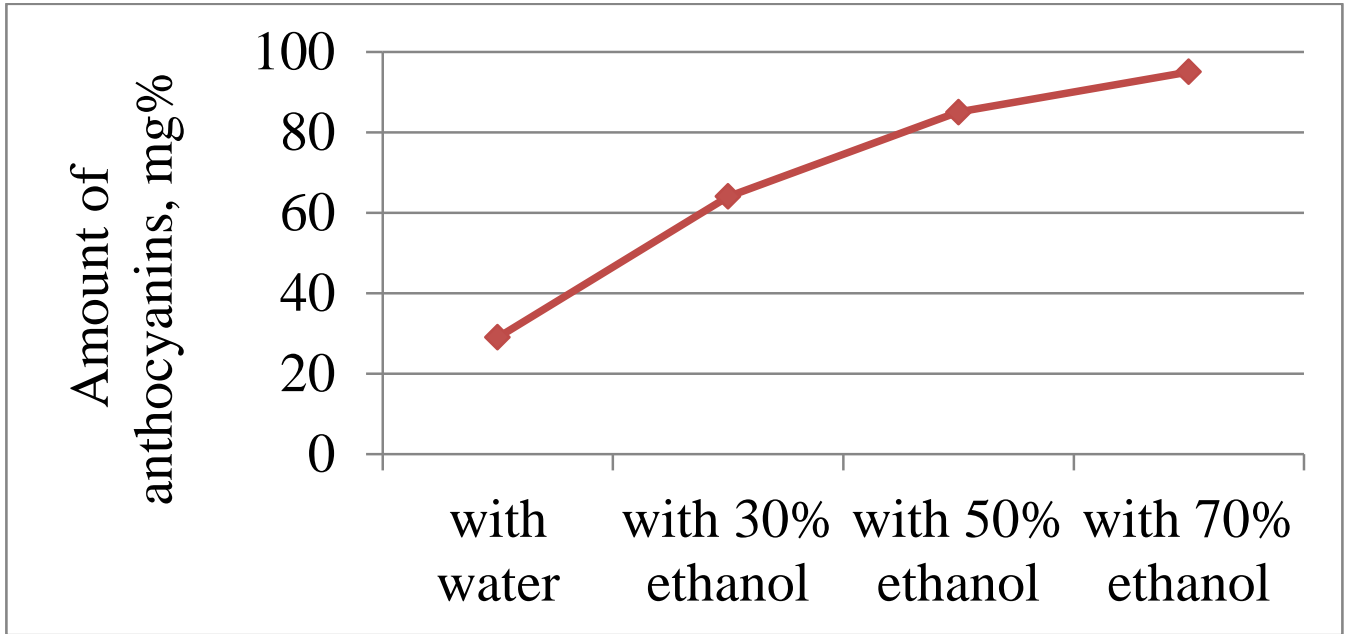

Figure 4. Effect of extractant concentration on anthocyanins content in extracts of dried fruits black blueberry

The change in tannins concentration follows the trend observed in other compounds of the phenolic complex (Figure 5).

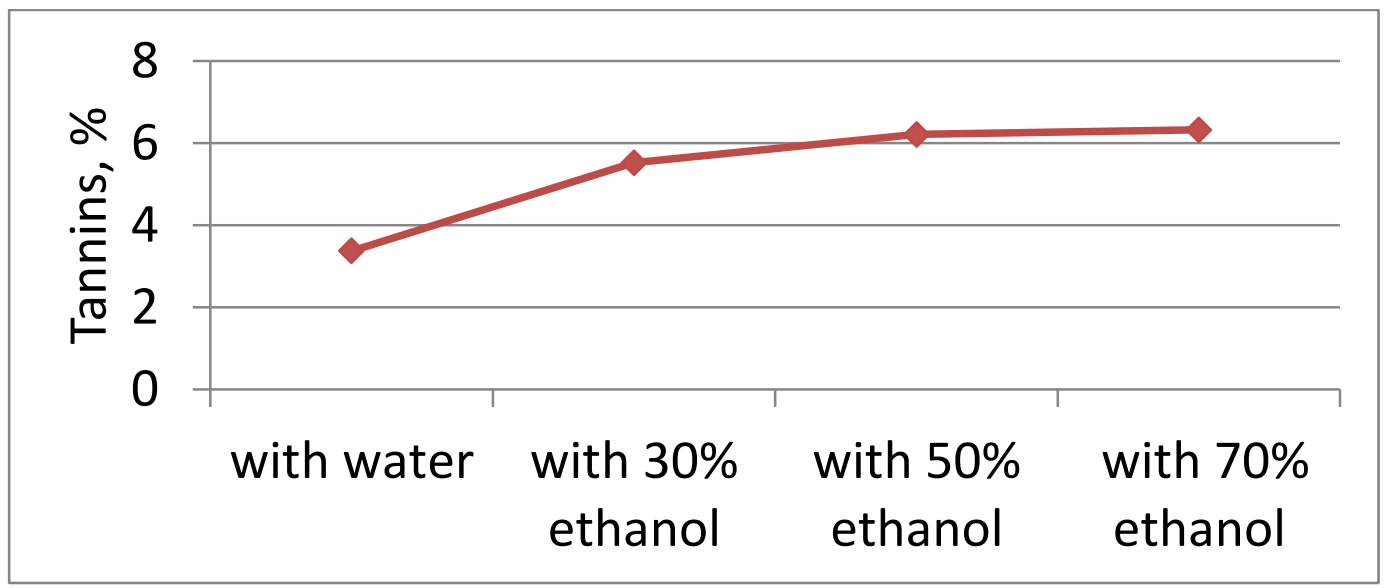

Figure 5. Effect of extractant concentration on the content of tanning substances in extracts of dried fruits black blueberry

Results of studies of the effect of extraction temperature on the physicochemical composition of black blueberry extracts are given in (Figures 6-10).

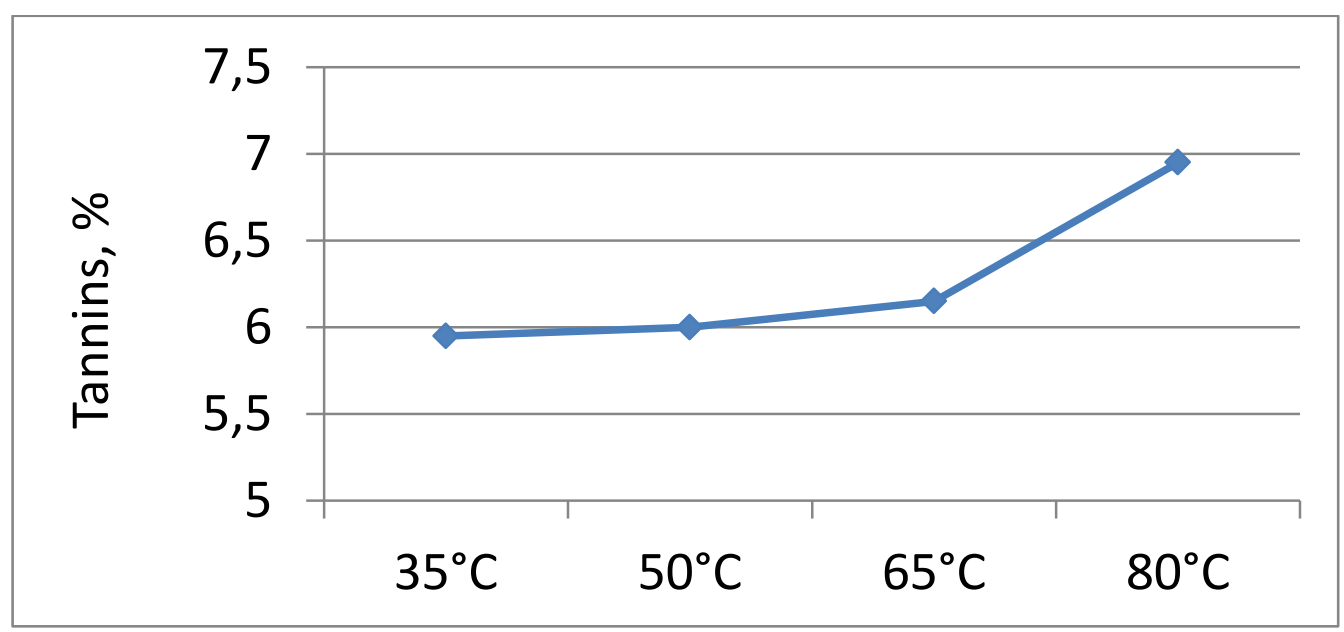

Figure 6. Effect of extractant concentration on the content of tanning substances in extracts of dried fruits black blueberry 


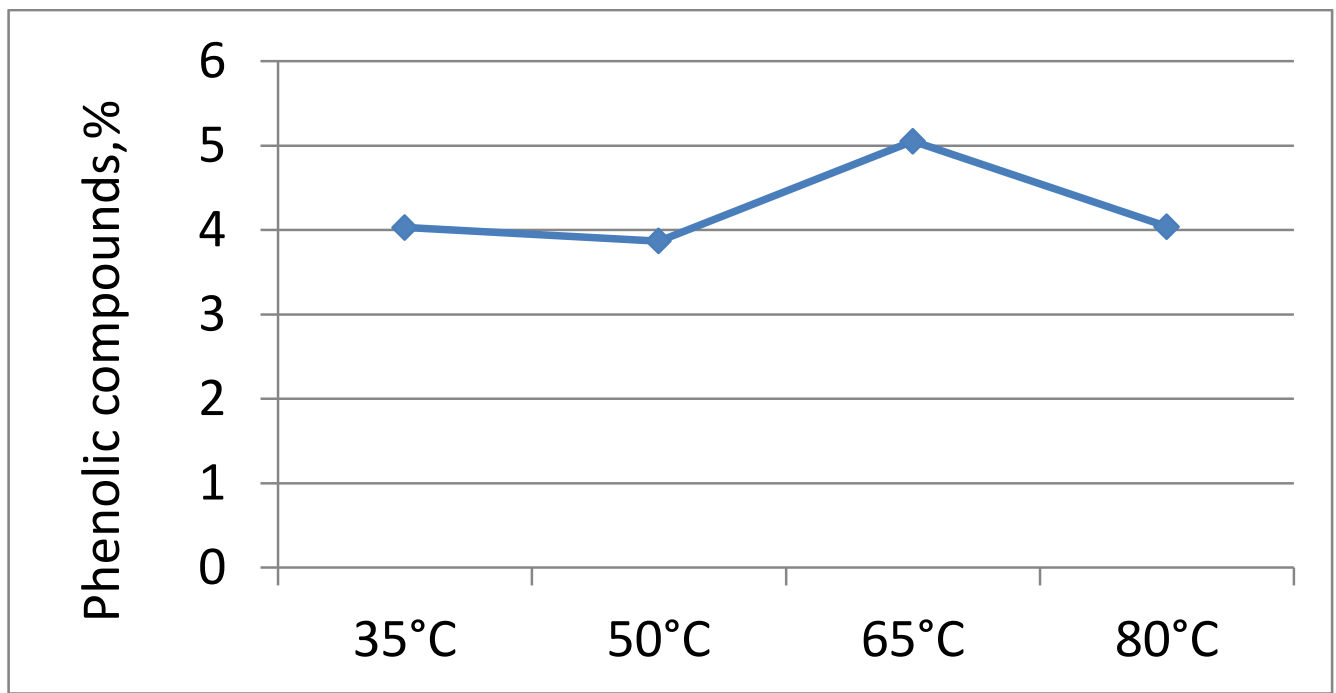

Figure 7. Influence of the extraction temperature on the total phenolic compounds content in extracts of dried fruits black blueberry

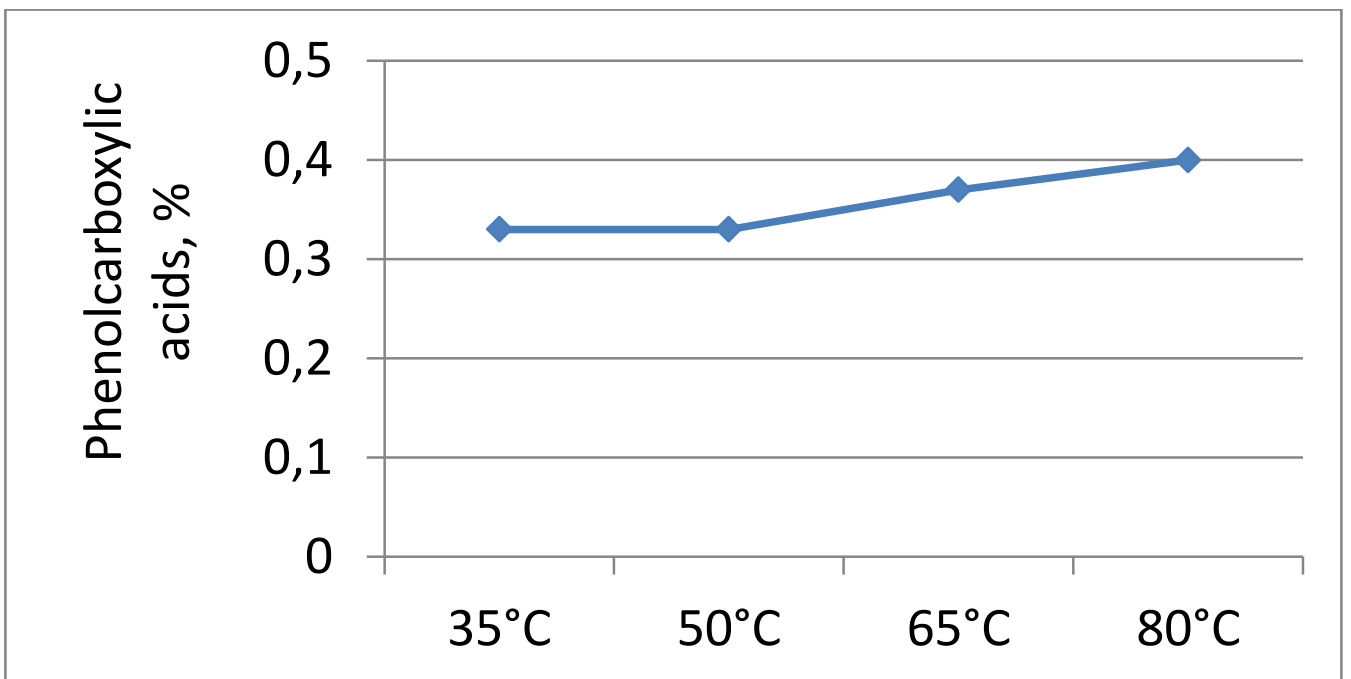

Figure 8. Influence of the extraction temperature on phenolcarboxylic acids content in extracts of dried fruits black blueberry

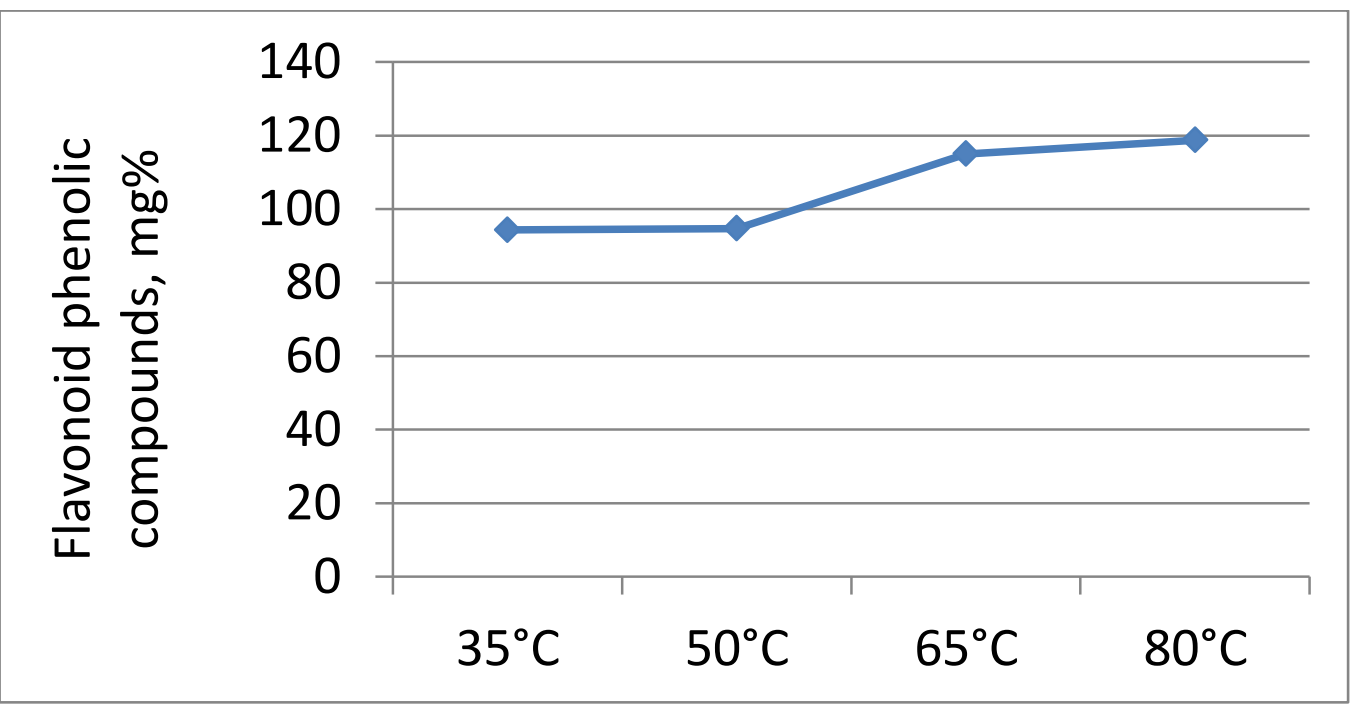

Figure 9. Influence of the extraction temperature on flavonoid phenolic compounds content in extracts of dried fruits black blueberry 
The sum of anthocyanins at different extraction temperatures is given in (Figure 10).

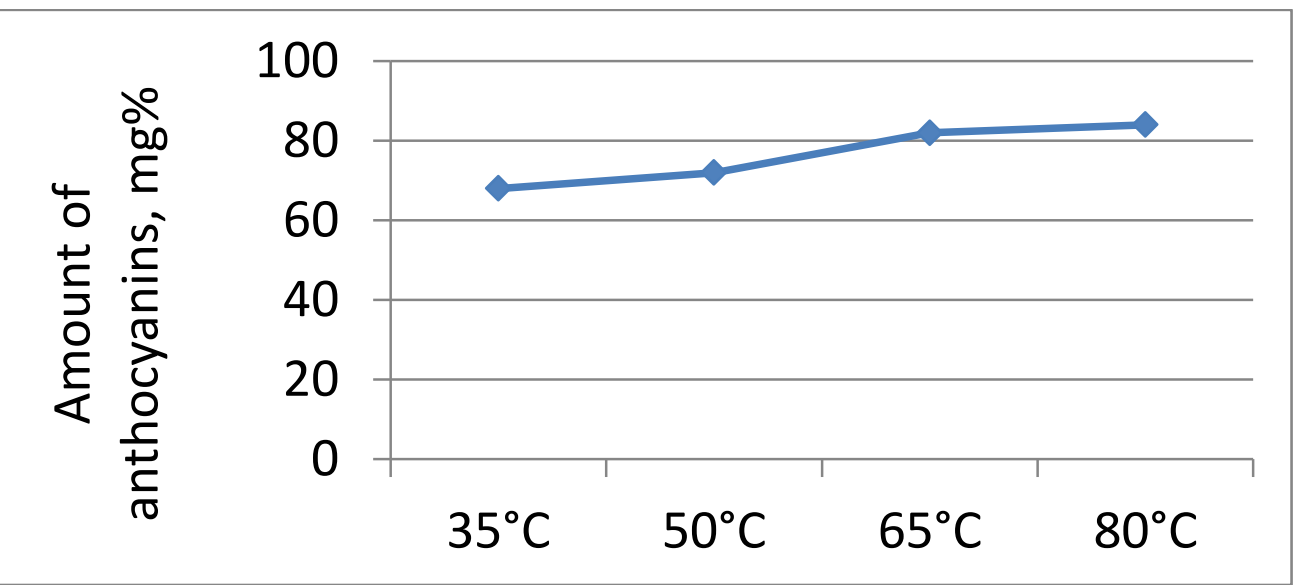

Figure 10. Influence of the extraction temperature on anthocyanins content in extracts of dried fruits black blueberry

Results of studies of the effect of extraction duration on the physicochemical composition of black blueberry extracts are given in (Figures 11-15).
The concentration of total phenolic compounds in black blueberry extracts varies depending on different time-temperature extraction regimes - (Figure 11).

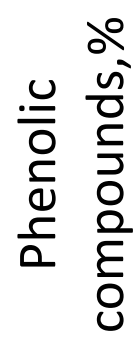

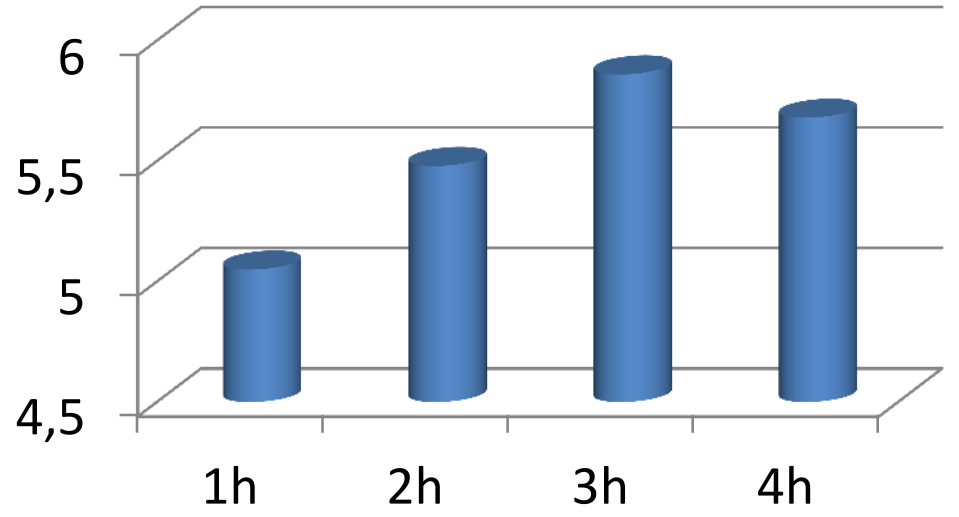

Figure 11. Influence of the duration of extraction on the content of the total phenolic compounds in extracts of dried fruits black blueberry
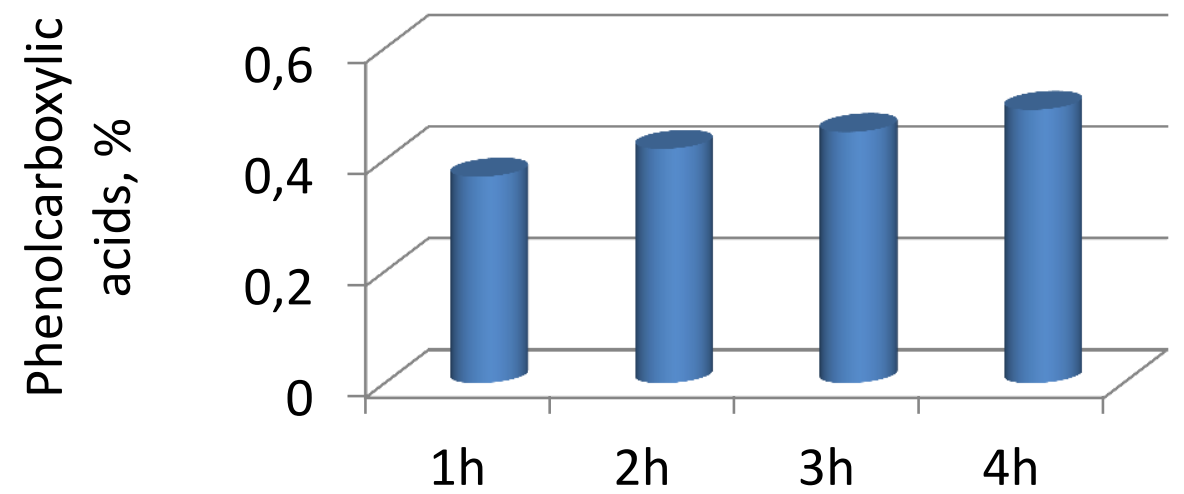

Figure 12. Influence of duration of extraction on the phenolcarboxylic acids content in extracts of dried fruits black blueberry 


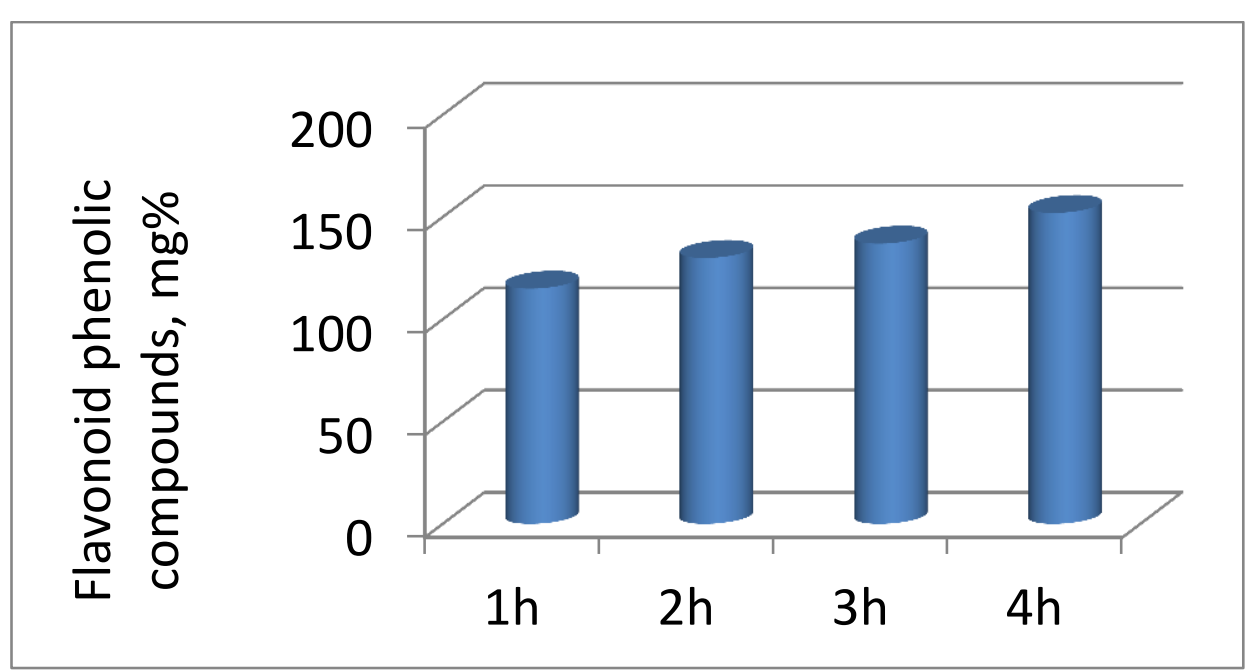

Figure 13. Influence of the duration of extraction on the content of flavonoid phenolic compounds in extracts of dried fruits black blueberry

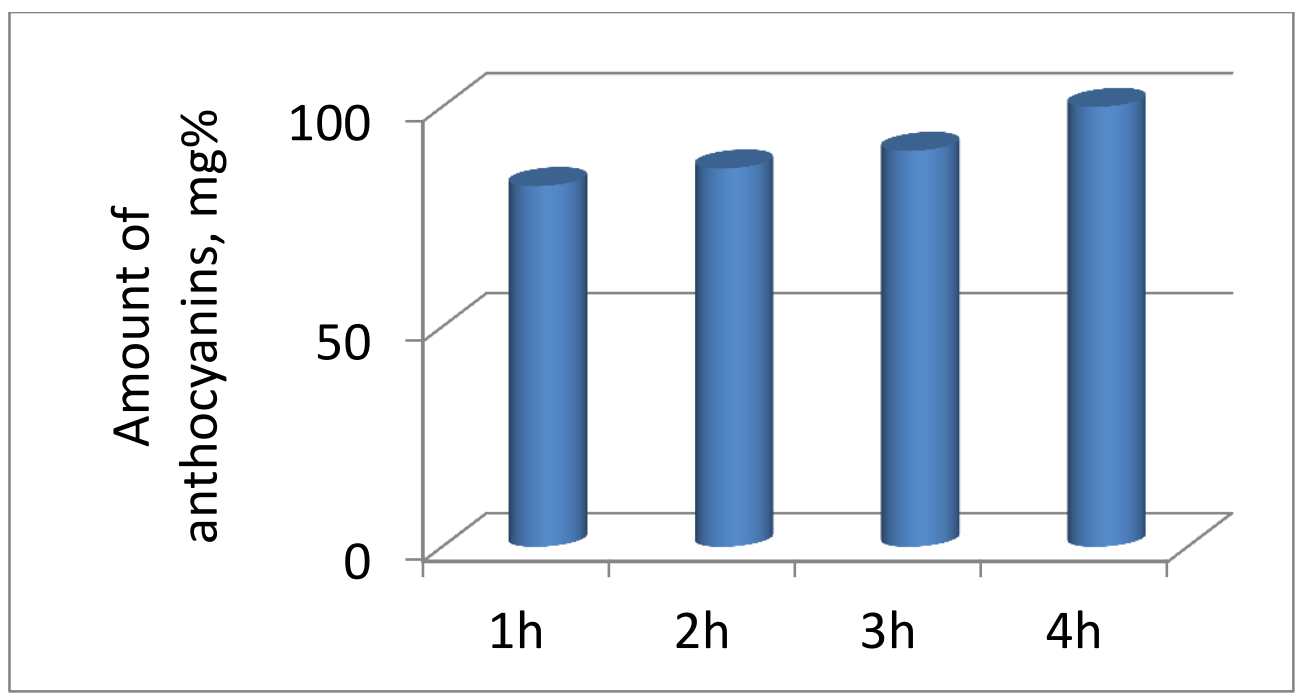

Figure 14. Influence of the duration of extraction on the amount of anthocyanins in extracts of dried fruits black blueberry

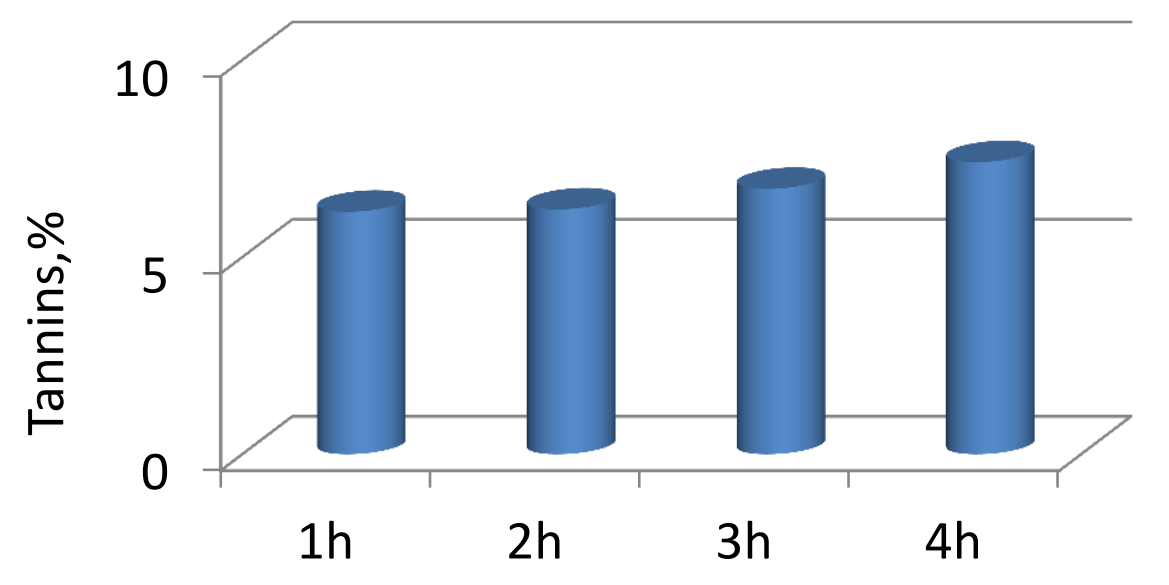

Figure 15. Influence of the duration of extraction on the content of tanning substances in extracts of dried fruits black blueberry

The effect of the extraction hydromodule on the content of some groups of compounds in the extracts obtained from black blueberry fruits was investigated (Figures 16-20). 


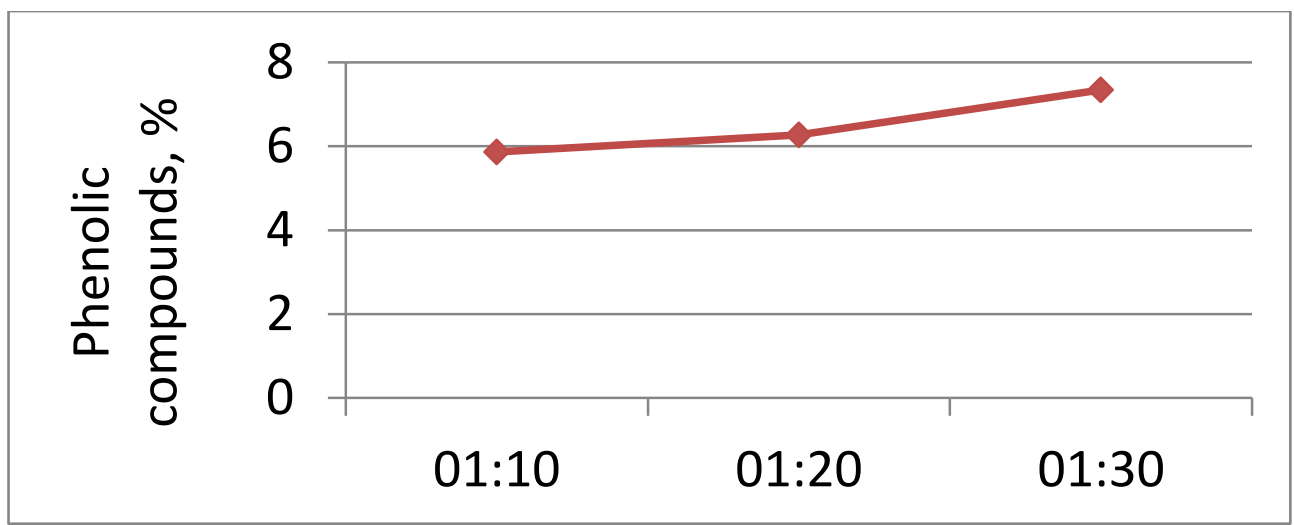

Figure 16. Influence of the extraction hydromodul on the content of the total phenolic compounds in extracts of dried fruits black blueberry

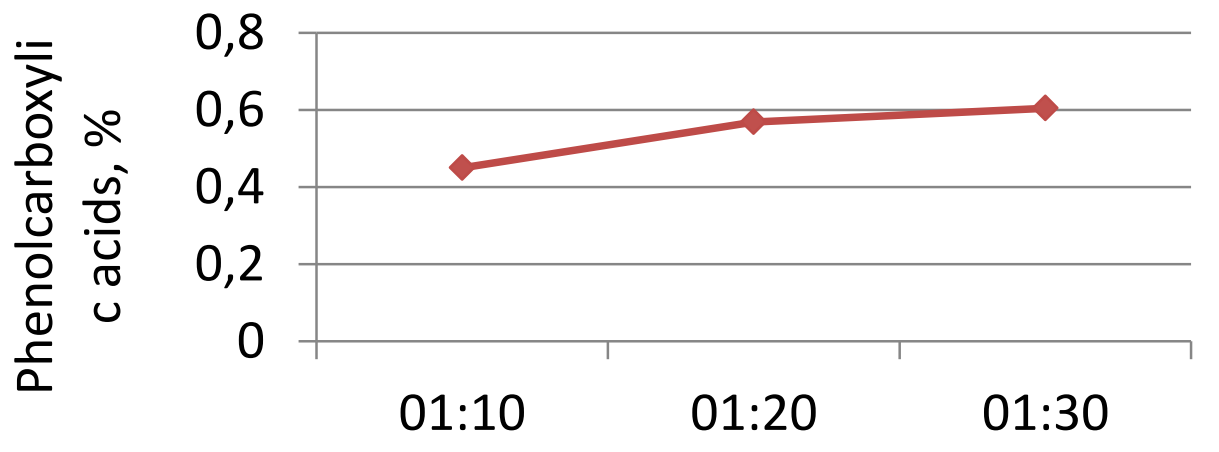

Figure 17. Influence of the extraction hydromodul on the phenolcarboxylic acid content in extracts of dried fruits black blueberry

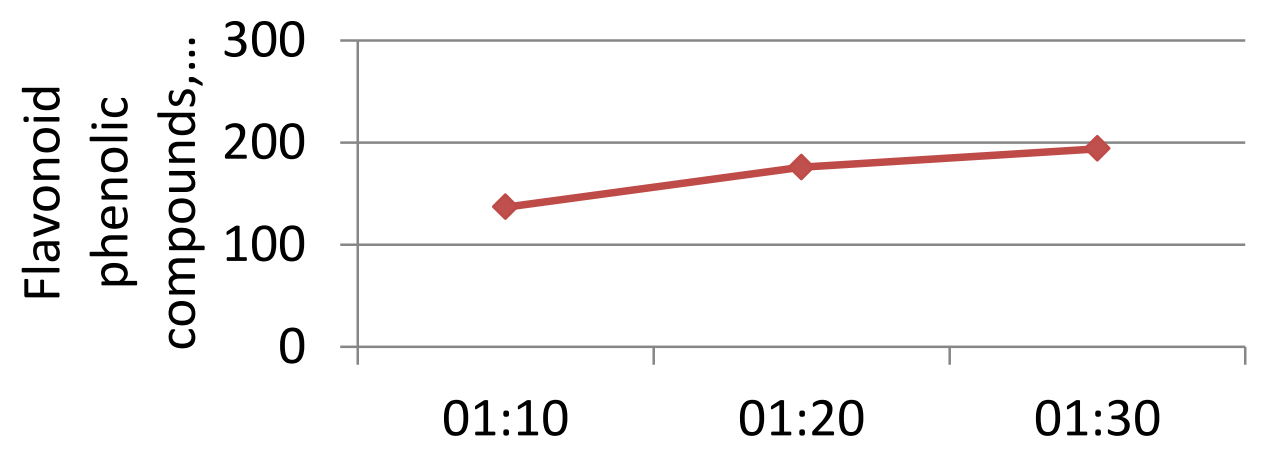

Figure 18. Effect of extraction hydromodul on the content of flavonoid phenolic compounds in extracts of dried fruits black blueberry

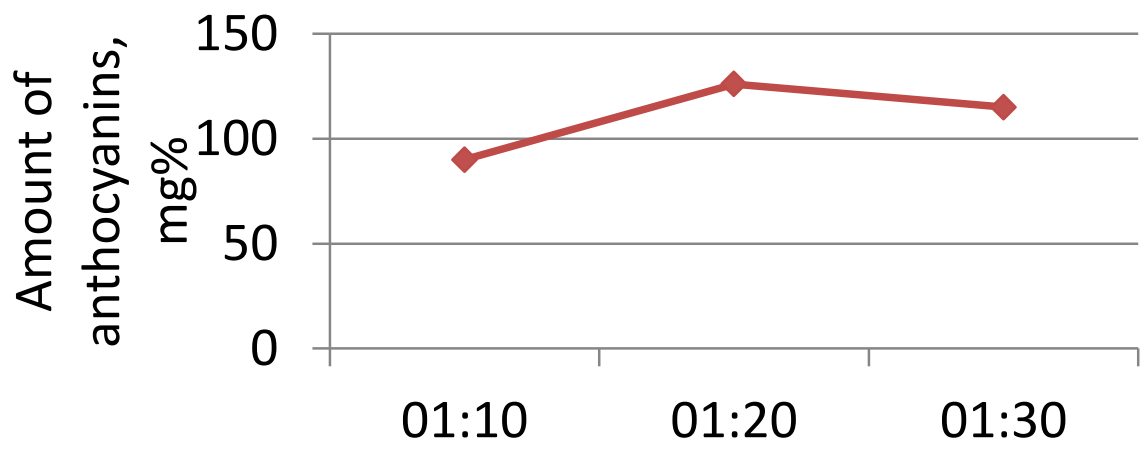

Figure 19. Influence of the extraction hydromodul on the sum of anthocyanins in extracts of dried fruits black blueberry 


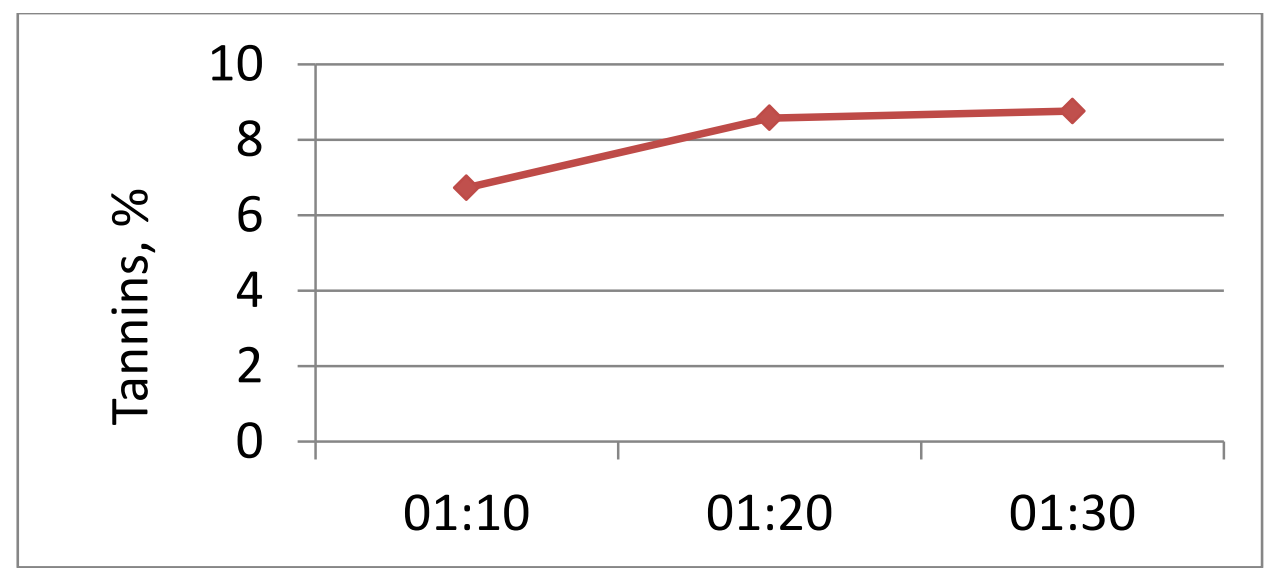

Figure 20. Influence of the extraction hydromodul on the content of tanning substances in extracts of dried fruits black blueberry

\section{DISCUSSION}

The concentration of total phenolic compounds is higher when extracted of dried fruits blackblueberry with ethyl alcohol compared to the extraction with water. It increases with increasing concentration of ethyl alcohol in the extracts, reaching its maximum in the extract with $70 \%$ ethyl alcohol.

On extraction of dried fruits blueberries with an increase in the concentration of ethyl alcohol from 30 to $50 \%$, the amount of total phenolic compounds increased by $15 \%$, and on extraction with $70 \%$ ethyl alcohol, they increased by $44 \%$ (Figure 1).

The concentration of phenol carboxylic acids upon extraction with $30 \%, 50 \%$ and $70 \%$ ethanol is higher than the aqueous extracts and is respectively $2.2 ; 2.3$ and 2.4 times higher (Figure 2). For flavonoid phenolic compounds, the increase in concentration was 1.8; 2.1 and 2.2 times (Figure 3).

The amount of anthocyanins increased in the same sequence, the highest being with $70 \%$ ethyl alcohol as an extractant and ranging from 29 to $95 \mathrm{mg} \%$ (Figure 4).

The amount of the tannins is highest in the extracts with $70 \%$ ethanol, respectively with $14.5 \%$ (Figure 5).

The content of tannins extracted from the dried blackblueberry varies from $5.95 \%$ to $6.95 \%$ at an extraction temperature of $35^{\circ} \mathrm{C}$ to $80^{\circ} \mathrm{C}$. The data show that as the temperature increases, the amount of tannins increases and their maximum value is at $80^{\circ} \mathrm{C}$ (Figure 6).

The content of total phenolic compounds in the extracts varied at different temperatures from $3.87 \%$ at $50{ }^{\circ} \mathrm{C}$ to $4.78 \%$ at $65{ }^{\circ} \mathrm{C}$ for blackblueberry . The technologically justified extraction temperature is $65^{\circ} \mathrm{C}$ (Figure 7).

The trend in the content of phenol carboxylic acids is similar to that of the flavonoid phenolic compounds. Favorable extraction temperature is $80^{\circ} \mathrm{C}$ (Figure 8 and Figure 9).

In chemical structure and action, anthocyanin glycosides are close to flavonoids. The anthocyanin glycosides contained in black blueberry fruits are particularly active. The highest is the total anthocyanins content of the extracts obtained at $80^{\circ} \mathrm{C}$ (Figure 10).

With an extraction duration of 1 hour to 3 hours, the concentration of total phenolic compounds increased from $5.22 \%$ to $5.86 \%$ by $12.3 \%$. By increasing the extraction time to 4 hours, their content decreases by $3.1 \%$ (Figure 11).

The content of phenolcarboxylic acids extracted from the dried fruits of the black blueberry varies from $0.37 \%$ with an extraction duration of 1 hour to $0.49 \%$ with an extraction lasting 4 hours. The increase is $32.4 \%$ (Figure 12).

A similar tendency is observed in the flavonoid phenolic compounds. Their concentration ranges from $115 \mathrm{mg} \%$ to $152 \mathrm{mg} \%$. The increase is in the order of $32.2 \%$ (Figure 13).

Similar to the flavonoid phenolic compounds is the increase in the amount of anthocyanins. At different extraction durations, they range from $82 \mathrm{mg} \%$ to $100 \mathrm{mg} \%$, with an increase of $21.9 \%$ (Figure 14).

The content of tannins extracted from black blueberry fruits by extraction at different extraction times varies from $6.15 \%$ to $7.41 \%$. 
The increase is respectively $20.5 \%$ (Figure 15).

The content of total phenolic compounds in the extracts varied for the various hydromodules from $5.86 \%$ for hydromodule $1: 10$ to $6.27 \%$ for hydromodule $1: 20$ and $7.34 \%$ for hydromodule 1:30. The technologically justified extraction hydromodule is 1:30 (Figure 16).

The phenolic carboxylic acids content extracted from the dried black blueberry fruits ranged from $0.45 \%$ with hydromodule $1: 10$ to $0.61 \%$ with hydromodule $1: 30$. The increase is by $35.5 \%$ (Figure 17).

A similar tendency is observed in the flavonoid phenolic compounds. Their concentrations ranged from $137 \mathrm{mg} \%, 176 \mathrm{mg} \%$ to $194 \mathrm{mg} \%$, respectively, for hydromodule $1: 10,1: 20$ to $1: 30$. The increase is in the order of $28.5 \%$ and $44.8 \%$ relative to the hydro modul 1:10 (Figure 18).

Studies of the sum of anthocyanins in black blueberry extracts obtained with three different hydromodules show that the anthocyanins content varies from $90 \mathrm{mg} \%$ to $126 \mathrm{mg} \%$ and $115 \mathrm{mg} \%$ in (Figure 19). A more significant increase in anthocyanins was observed in black blueberry extracts at hydromodule 1:20. This is probably due to the greater extractability of this component due to the improved solubility and mass transfer.

The content of tannins extracted from dried black blueberry varies from $6.73 \%$ to $8.76 \%$ in the case of hydromodule $1: 10$ to $1: 30$. The data show that the hydromodule influences the amount of tannins and their maximum value depends on the ratio of the raw material and the extractant (Figure 20).

The results obtained allow us to conclude that, according to the total content of the phenolic complex, the most favorable hydromodule for performing the extraction is 1:30.

For the normal functioning of the body's complex antioxidant system, a wide range of biooxidants is required. Particularly effective is a systems in combination with the phenolic compounds contained in black blueberry extracts, which themselves function as active antioxidants.

\section{CONCLUSIONS}

1. The use of $70 \% \mathrm{C}_{2} \mathrm{H}_{5} \mathrm{OH}$ as an extractant is technologically warranted to produce extracts of dried fruits black blueberry with maximum content of phenols, flavonoids, anthocyanins and tannins.

2. Technologically justified extraction temperature is $65-80 \mathrm{oC}$. By increasing the extraction temperature to $80^{\circ} \mathrm{C}$, the quantity of anthocyanins in the extracts increases, which positively affects the organoleptic evaluation of the final products.

3. The optimum extraction time is 3-4 hours. During this extraction period, a maximum content of the phenolic complex is obtained.

4. On the basis of the experimental data, the technological regimes of the extraction process were selected.

\section{REFERENCES}

1. Kudrin AV Immunopharmacology of micronutrients / A.V. Kudrin, A.V. Skalny, A.V. Larks. - M .: Medicine, - 537 p., 2000.

2. Nutrition in preventive medicine: major syndromes of nutritional deficiency, epidemiology and ways to combat them / ed. G.H. Bit-na, D.M. Bengois. - M .: Medicine, 380, 1985

3. C. A. Rice-Evans, N. J. Miller, and G. Paganga, "Structureantioxidant activity relationships of flavonoids and phenolics acids," Free Radical Biology and Medicine, vol. 20, no. 7, pp. 933-956, 1996.

4. G. J. McDougall, N. N. Kulkarni, and D. Stewart, "Berry polyphenols inhibit pancreatic lipase activity in vitro," Food Chemistry,vol.115,no.1,pp.193-199,2009.

5. Harborne JB, Williams CA. Advances in flavonoid research since. Phytochemistry. 2000;55(6): 481-504, 1992.

6. Ames BN, Shigenaga MK, Hagen TM. Oxidants, antioxidants, and the degenerative diseases of aging. Proc Natl Acad Sci USA. 90(17):7915-7922, 1993.

7. Hou DX. Potential mechanisms of cancer chemoprevention by anthocyanins. Curr Mol Med. 3(2):149-159 2003.

8. Bagchi D, Sen CK, Bagchi M, Atalay M. Antiangiogenic, antioxidant, and anticarcinogenic properties of a novel anthocyanin-rich berry extract formula. Biochemistry (Mosc). 69(1):75-80, 2004.

9. Katsube N, Iwashita K, Tsushida $\mathrm{T}$, Yamaki K, Kobori M. Induction of apoptosis in cancer cells by bilberry (Vaccinium myrtillus) and the anthocyanins. J Agric Food Chem. 51(1):68-75, 2003.

10.State Pharmacopoeia of Russia. General methods of analysis - II ed., Medicine, 1987. 